\title{
Injuries among adolescents in Greenland: behavioural and socio-economic correlates among a nationally representative sample
}

\author{
Louis Jansen ${ }^{\text {Corresp., } 1}{ }^{\text {, Till Bärnighausen }}{ }^{1}$, Michael Lowery Wilson ${ }^{1,2}$ \\ 1 Heidelberg Institute of Global Health, Ruprecht-Karls-Universität Heidelberg, Heidelberg, Baden-Wuerttemberg, Germany \\ 2 Injury Epidemiology and Prevention (IEP) Research Group, Turku Brain Injury Centre, Department of Clinical Neurosciences, Turku University Hospital, \\ University of Turku, Turku, Finland \\ Corresponding Author: Louis Jansen \\ Email address: louis.jansen@gmx.net
}

\begin{abstract}
Background. Injuries are among the most important threats to adolescent health, making examination of the patterns and risk factors a critical area of research. There exists a paucity of information on the health and injury experience of school-attending adolescents in Greenland. Consenting Greenlandic schoolchildren $(n=2254)$ aged 9 to 19 years were included in the Health Behavior in School-Aged Children (HBSC) study 2005/2006. The aim of this study was to examine the socioeconomic and behavioural correlates that were associated with injury occurrence among school-attending Greenlandic adolescents.
\end{abstract}

Methods. This study made use of two multinomial regression models to examine injury occurrence regarding potential influencing factors such as physical activity, risk behaviors, bullying and family socioeconomic status.

Results. Those self-reporting 1-2 injuries within the recall period were more likely to be male $(O R=1.70$; $\mathrm{Cl}=1.39-2.09)$, involved in physical fighting (OR=1.82; $\mathrm{Cl}=1.33-2.47)$, bullied $(\mathrm{OR}=1.81 ; \mathrm{Cl}=1.47-2.24)$ and participated in bullying others $(\mathrm{OR}=1.53 ; \mathrm{Cl}=1.25-1.89)$. Those reporting three or more injuries were again mostly male $(\mathrm{OR}=2.13 ; \mathrm{Cl}=1.44-3.14)$, involved in physical fighting at higher rates $(\mathrm{OR}=4.47$; $\mathrm{Cl}=2.86-7.01)$, bullied more often $(\mathrm{OR}=2.43 ; \mathrm{Cl}=1.65-3.57)$ and were more likely to bully others $(\mathrm{OR}=1.67 ; \mathrm{Cl}=1.13-2.45)$. Living without a mother proved to be significantly correlated with suffering 3 or more injuries during the recall period $(\mathrm{OR}=1.63 ; \mathrm{Cl}=1.05-2.52)$. The study results support the idea that factors that were found to be associated with injury occurrence, such as bullying and aggressive behaviour, should be taken into account when conducting future research on the nature of injuries among Greenlandic adolescents. More research on this topic is needed to identify factors that might modify the associations between injuries and adolescent behaviour and socioeconomic status. 
1 Injuries among adolescents in Greenland: behavioural and socio-economic

2 correlates among a nationally representative sample

3 Louis Jansen $^{\mathrm{a} *}$, Till Bärnighausen ${ }^{\mathrm{a}}$ and Michael Lowery Wilson ${ }^{\mathrm{a}, \mathrm{b}}$

$4{ }^{a}$ Heidelberg Institute of Global Health, Ruprecht-Karls-University, Heidelberg, Germany;

$5{ }^{b}$ Injury Epidemiology and Prevention (IEP) Research Group, Turku Brain Injury Centre,

6 Department of Clinical Neurosciences, Turku University Hospital, University of Turku, Finland

8 Louis Jansen

9 Czernyring 30

1069115 Heidelberg

11 Germany

12 *Mail: Louis.Jansen@stud.uni-heidelberg.de

13 Phone: +49 1776448664

14

15

16

17

18

19

20

21

22

23

24

25

26 


\section{Abstract}

29 Background. Injuries are among the most important threats to adolescent health, making examination of the patterns and risk factors a critical area of research. There exists a paucity of information on the health and injury experience of school-attending adolescents in Greenland.

Behavior in School-Aged Children (HBSC) study 2005/2006. The aim of this study was to examine the socioeconomic and behavioural correlates that were associated with injury occurrence among school-attending Greenlandic adolescents .

Methods. This study made use of two multinomial regression models to examine injury occurrence regarding potential influencing factors such as physical activity, risk behaviors, bullying and family socioeconomic status.

Results. Those self-reporting 1-2 injuries within the recall period were more likely to be male $(\mathrm{OR}=1.70 ; \mathrm{CI}=1.39-2.09)$, involved in physical fighting $(\mathrm{OR}=1.82 ; \mathrm{CI}=1.33-2.47)$, bullied $(\mathrm{OR}=1.81 ; \mathrm{CI}=1.47-2.24)$ and participated in bullying others $(\mathrm{OR}=1.53 ; \mathrm{CI}=1.25-1.89)$. Those reporting three or more injuries were again mostly male (OR=2.13; $\mathrm{CI}=1.44-3.14)$, involved in physical fighting at higher rates $(\mathrm{OR}=4.47 ; \mathrm{CI}=2.86-7.01)$, bullied more often $(\mathrm{OR}=2.43$; mother proved to be significantly correlated with suffering 3 or more injuries during the recall period ( $\mathrm{OR}=1.63$; $\mathrm{CI}=1.05-2.52)$. The study results support the idea that factors that were found to be associated with injury occurrence, such as bullying and aggressive behaviour, should be taken into account when conducting future research on the nature of injuries among Greenlandic adolescents. More research on this topic is needed to identify factors that might modify the associations between injuries and adolescent behaviour and socioeconomic status. 


\section{(1) Introduction}

52 Injuries among adolescents has emerged as a global problem of public health importance. It is

53 estimated by the World Health Organization (WHO), that injuries account for almost one million

54 deaths annually among young people under the age of 18 years worldwide, making it one of the

55 most urgent adolescent health concerns (Djerboua et al. 2016). From the age of one year until

56 adulthood, injuries account for a major portion of adolescent deaths. Even though ways to

57 decrease the likelihood and severity of injuries are known, prevention and awareness still trail

58 behind the current state of research (Peden et al. 2009). Considering that effective measures to

59 prevent injuries do exist, it must be a focal point of injury research to determine what puts

60 adolescents at risk for and protects them against injuries.

61 Injuries can be divided into two major areas: those which are violence-related or

62 intentional injuries and unintentional injuries, so called “accidents”. As both the World Report on

63 Violence against Children and the World Report on Child Injury Prevention state, prevention of

64 violence and injury respectively is the key for improving adolescents’ well-being (Peden et al.

65 2009; Pinheiro \& Children 2006).

66 The most common causes of unintentional injuries among adolescents are road traffic

67 injuries, drowning, and other causes (including categories such as smothering, asphyxiation,

68 bites, hypo/hyperthermia and natural disasters). Risk factors these causes share are poverty, lack

69 of supervision or care and often but not always male gender (Peden et al. 2009). In high-income

70 countries road traffic and drowning related injuries account for more than two thirds of all

71 unintentional injury deaths among people aged less than 20 years. To compare, in low- and

72 middle-income countries other causes (including categories such as smothering, asphyxiation,

73 bites, hypo/hyperthermia and natural disasters) and road traffic injuries account for more than 60

74 percent of all deaths in under 20 year olds (Harvey et al. 2009). 
76 psychological integrity in ways that range from harmless to possibly life-threatening. The

77 devastating effect of adolescent violence was described by David-Ferdon \& Simon in 2014, when

78 they showed that more U.S. youth die from homicide each year than from cancer, heart disease,

79 birth defects, flu and pneumonia, respiratory diseases, stroke, and diabetes combined.

80 International research has shown that social marginalization and adverse familiar circumstances

81 (e.g. familiar abuse and neglect) as well as drug abuse and economic inequality can be considered

82 as risk factors for being involved in violence (David-Ferdon \& Simon 2014; Kobusingye et al.

83 2010). Protective factors include a safe and care-giving familiar environment, strong social bonds

84 outside of the family, an understanding of responsible drug use, and high socio-economic status

85 (Bushman et al. 2016).

86 Despite the importance of research on injury and violence among Greenlandic

87 adolescents, research on it remains sparse. The last English-language paper addressing the topic

88 of adolescent aggression, which is one of many risk factors for adolescent injuries (Laflamme et

89 al. 2002), was written by Schnohr \& Niclasen in 2006. The authors reported an increase in the

90 prevalence of bullying in Greenlandic schools. In comparison to 35 other countries (located in

91 Europe and North America) Greenland ranked $7^{\text {th }}$ in terms of bullying others several times during

92 the month preceding survey. Greenlandic schoolchildren showed above-average percentages for

93 bullying others as well (Schnohr \& Niclasen 2006). Those numbers stress the need of further

94 research to be conducted on the topic of injuries among Greenlandic adolescents and their socio-

95 economic and behavioural correlates. The aim of this study was to examine the socioeconomic

96 and behavioural correlates for injuries among a nationally representative sample of school-

97 attending adolescents in Greenland. 


\section{(2) Materials \& Methods}

99

100

101

102

103

104

105

106

107

108

109

110

111

112

113

114

115

116

117

118

119

120

121

\subsection{Setting}

The current study is based on data collected in Greenland, the world's largest island. Greenland is an autonomous territory within the Kingdom of Denmark. The population is 56,225, making it the most sparsely populated territory on earth. Children and adolescents of school age, classified as being between 5 to 19 years of age, make up a total of 11,291 inhabitants, accounting for 20.1\% of the total population (Blaabjerg 2019). The gross domestic product (GDP) per capita is USD\$ 41,800 (Agency \& Office 2016) and the Human Development Index (HDI) is 0.786 (Avakov 2015), which both classify Greenland as a highly developed country.

\subsection{Sample}

In Greenland, 2,254 secondary school students (52\% females) aged 9 - 19 years with a mean age of 13.4 years participated in the survey. The final sample included 2,217 participants, as 37 participants had to be excluded since they did not have complete information on the variables age or gender. All Greenlandic schools with more than ten students were invited to take part in the survey. If the school board had decided to participate, they were then provided with the questionnaires. A Greenlandic- and Danish-language paper questionnaire was administered by a teacher. Detailed information about the questionnaire, data collection methods and study design can be found on the HBSC website - http://www.hbsc.org/ and the HBSC Greenland website http://www.hbscgreenland.org/. Passive consent from adolescents participating in the HBSC survey was obtained. The resulting dataset was stripped of potentially identifying characteristics. No individual participant was contacted during or after the research period.

\subsection{Measurements}

The data for this study was derived from Greenland's contribution to the Health Behaviour in School-aged Children survey (HBSC) in 2005/2006. The HBSC study was adopted by the WHO 
122 in 1983 to cross-sectionally survey 11-, 13- and 15-year-old boys' and girls' health and well-

123 being, social environments and health behaviours. Since then it has been conducted every four.

124 The questions that were analysed in this study are depicted in the appendix named 'Appendix 1'.

125 In accordance with suggestions from the peer-reviewed literature, we examined the following

126 independent variables: gender, age, vigorous physical activity (VPA), VPA (outside school

127 hours), smoking, alcohol misuse, physical fighting, bullying victimization, bullying perpetrator,

128 parent socio-economic status, living with parents \& self-assessed wealth (Acquah et al. 2014a;

129 Acquah et al. 2014b; Celedonia et al. 2013; Garmy et al. 2018). The relevant questions and

130 examined variables and coding can be found in the appendix under the name 'Appendix 1'.

\section{$131 \quad 2.4$ Statistical Analysis}

132 Our analyses focused on covering a spectrum of risk and protective factors that have been

133 observed to play a role in injury occurrence among adolescents in school environments.

134 Participants were divided into three groups: those not reporting any injuries throughout the 12

135 months preceding the survey (“No Injuries”), those reporting one or two injuries (“1-2 Injuries”)

136 and those reporting three or more injuries (“3+ Injuries”). The question "During the past 12

137 months, how many times have you been injured?” had five response options. Those were “ 1 = I

138 have not been injured”, “ $2=$ Once”, “ $3=$ Twice”, “ $4=3$ times” and “ $5=4$ times or more”.

139 Injuries were defined in the official HBSC survey form as injuries that required medical attention.

140 The literal question specifically included injuries that resulted from playing sports, fighting with

141 someone else at different places such as the street or at home, being poisoned, or being burned.

142 Illnesses such as measles or the flu were specifically excluded in the literal question, while both

143 intentional and unintentional injuries were included.

144 The distribution of selected variables within each of the three injury occurrence categories

145 was examined initially. Significant differences between each category and independent variables 
146 were explored using Pearson's chi-squared test for categorical variables and multinomial

147 regression for the continuous variable age. Then two multinomial logistic regression (MLR)

148 models were used to examine independent variable associations with those who reported no

149 injuries, those reporting 1-2 injuries and those reporting 3+ injuries while adjusting for

150 covariates. The cut points were selected after distributional aspects (Table 1) in combination with

151 observations in the peer-reviewed literature (Acquah et al. 2014b). In comparison to binary

152 logistic regression (BLR), MLR allows to examine the probabilities of more than two distinct

153 outcomes. In the study the dependent variable had 3 possible outcomes, which made MLR more

154 suitable than BLR. The first MLR model included all variables that were shown to be significant

155 in the bivariate analyses ( $<<0.05)$. The second model was adjusted only for age and sex. To

156 measure the strength of the associations between the dependent variable and the independent

157 variables we calculated odds ratios (OR) and their respective 95\% confidence intervals (CI). All

158 analyses were conducted using the R Statistical Environment for Windows 10 (R Development

159 Core Team 2010).

160

(3) Results

161 Within the recall period (1 year), 30\% of sampled adolescents reported having been injured, 24\%

162 of whom reported 1-2 injuries and 6\% reported 3 or more injuries. Of the 1-2 Injuries group 57\%

163 were male and of the 3+ Injuries group 62\% were male. The overall mean age of our sample was

$16413.4(\mathrm{SD}=1.7)$. Those reporting alcohol misuse constituted $11.2 \%$, 36\% reported smoking

165 tobacco and 12\% reported being involved in a physical fight within the last 12 months. Being a

166 victim of bullying was affirmed by $37.5 \%$ while $42.7 \%$ reported having bullied others. Of the

167 participating adolescents $78.7 \%$ lived together with their mother, while $60.6 \%$ confirmed living

168 together with their father. Living together with both parents was affirmed by $52.5 \%$. A high

169 maternal socioeconomic status (SES) was confirmed by $47.1 \%$, while $41.3 \%$ classified their 
170 father's SES as high. When asked to assess their own family’s wealth $73.5 \%$ assessed it as

171 average, 7.3\% as below-average, and 19.2\% as above-average. Practising VPA on 4 or more days

172 a week was affirmed by 49.7\%, while 50.8\% practised VPA outside of school 4 days or more a

173 week.

174 Table 1 depicts the distribution of the independent variables within the three categories of

175 the dependent variable. Significance was found in the psychological and physical aggression

176 category (Bullying victimization, Bullying perpetrator, Physical fighting) and in social categories

177 such as living together with their mother. Furthermore, being male and practising VPA outside of

178 school settings yielded higher percentages of injury occurrence. Of the aforementioned results

179 only living together with the mother had a protective effect against injury occurrence. All other

180 factors were found to have increased the occurrence of self-reported injuries. No significant

181 differences were found with respect to age, substance use or economic status. Further factors that

182 did not prove to be significant were living with fathers, VPA and talking to friends of the same

183 and opposite gender.

184 After adjusting for all covariates, the first regression model delivered the following results

185 (Table 2). Those who were injured once or twice within the one year preceding the survey were

186 found to been bullied more often $(\mathrm{OR}=1.58$; $\mathrm{CI}=1.25-1.99)$. Involvement in physical fighting

187 increased the risk for injuries significantly $(\mathrm{OR}=1.58$; $\mathrm{CI}=1.14-2.20)$. Males were

188 overrepresented among those who reported being injured once or twice $(\mathrm{OR}=1.54$; CI $=1.23$ -

189 1.93).

190 The significant associations between getting injured three times or more were being male

$191(\mathrm{OR}=1.62 ; \mathrm{CI}=1.05-2.51)$, being bullied $(\mathrm{OR}=2.29 ; \mathrm{CI}=1.48-3.54)$ and being involved in a

192 physical fight $(\mathrm{OR}=3.42 ; \mathrm{CI}=2.09-5.59)$.

193 The second regression model was adjusted only for age and gender. The results are

194 summarized below in Table 3. Those who reported being in a fight $(\mathrm{OR}=1.82 ; \mathrm{CI}=1.33-2.47)$, 
195 being bullied $(\mathrm{OR}=1.81 ; \mathrm{CI}=1.47-2.24)$ and having bullied others $(\mathrm{OR}=1.53 ; \mathrm{CI}=1.25-1.89)$

196 were more likely to have been injured once or twice. Males were also at a higher risk to be

197 injured once or twice $(\mathrm{OR}=1.70 ; \mathrm{CI}=1.39-2.09)$.

$198 \quad$ Significant associations were found between being injured 3 times or more and being

199 male $(\mathrm{OR}=2.13 ; \mathrm{CI}=1.44-3.14)$, physical fighting $(\mathrm{OR}=4.47 ; \mathrm{CI}=2.86-7.01)$, being bullied

$200 \quad(\mathrm{OR}=2.43 ; \mathrm{CI}=1.65-3.57)$ and bullying others $(\mathrm{OR}=1.67 ; \mathrm{CI}=1.13-2.45)$. Living without a

201 mother was found to be associated with the experience of three or more injuries as well $(\mathrm{OR}=$ 202 1.63; CI = 1.05-2.52).

\section{(4) Discussion}

204 This study results suggest that the incidence in Greenland for having experienced a medically

205 attended injury at least once within a one-year period of recall was $24.2 \%$, whereas the average

206 cross-national incidence for injuries among school-attending adolescents from all countries that

207 participated in the HBSC survey ranks higher with 34.2\%. The Greenlandic incidence for injuries

208 among school-attending adolescents from 9-19 years for being injured three times or more was

$2095.6 \%$. That is also lower than the average cross-national incidence of 9.4\% (Currie et al. 2008).

210 Most of the participating countries (full list of the participating countries: http://www.hbsc.org/)

211 had a similar or higher GDP and HDI than Greenland at the time the survey was conducted.

212 Greenlandic students also reported lower rates of witnessing other people being injured or killed

213 in comparison to Iceland, the Faeroe Islands or Denmark (Karsberg et al. 2012). Transportation in

214 many areas of Greenland during the summer can only be achieved by air or sea, whilst in the

215 winter travelling on sea ice becomes a valuable traffic component as well (Grydehøj 2014). The

216 lack of large roads and car traffic compared to other highly developed countries may have

217 implications for the occurrence of road traffic related injuries in Greenland. Since those make up

218 around 57\% of all unintentional childhood injury deaths, it could be a possible explanation for the 
219 observed lower injury incidence rate in Greenland (Peden et al. 2009).

220 Injuries have long been known to be more prevalent amongst males, who accounted for

221 about 68\% of all injury-related deaths in 2010 (Lozano et al. 2012). It was shown that male

222 adolescents accounted for 57\% (1-2 Injuries) and 62\% (3+ Injuries) of all injuries in the

223 respective groups.

224 We did not find evidence for injuries to be associated with alcohol misuse or smoking.

225 Historically, Greenlandic adolescents have been more likely to engage in smoking and binge

226 drinking behaviour (Niclasen \& Bjerregaard 2007). Even though the impact of inebriation on

227 injury severity remains unclear, research has found that alcohol consumption and smoking have

228 been linked to the suffering of injuries in adolescents (Cherpitel et al. 2015; Knapik \& Bedno ;

229 Peden et al. 2009; Valdez et al. 2016). The mean age of our study's participants was 13.4 years

230 (SD: 1.74). In 2010 Rehm \& Shield pointed out that alcohol-attributable deaths among

231 adolescents (0-15 years of age) only account for 0.1 percent of all adolescent deaths worldwide

232 (Rehm \& Shield 2013). Skala \& Walter also considered the age of 15 to be a threshold after

233 whicha rise in repetitive excessive alcohol consumption can be observed (Skala \& Walter 2013).

234 Further, the HBSC international report from 2005/06 points out significantly higher rates of

235 drunkenness among 15-year olds than among 11- or 13-year olds (Currie et al. 2008). This

236 potentially illustrates that the present study sample may have been too young to be exposed to

237 excessive alcohol consumption behaviour, hence significant associations could not be found.

238 Lastly, it remains difficult to assess alcohol consumption through a questionnaire as the imprecise

239 recall of alcohol consumption may drive an association to the null (Wilson et al. 2012). The

240 prevalence of smoking in the present sample was found to be higher than in other high-income

241 countries. Almost 26\% of all participants reported smoking daily and 36\% report smoking more

242 or less regularly. In comparison, daily smoking prevalence for US American high school students 
243 ranks between 9 and 22\% (Siqueira et al. 2000). The association between smoking and injury has

244 been subset into four categories of reasoning: direct toxicity, distractibility, associated medical

245 conditions, and confounding factors (Sacks \& Nelson 1994). Since the theories of direct toxicity

246 and distractibility are either still questionable or only applicable to drivers, they do not aid to

247 explain a possible relationship between injuries and smoking within our study’s cohort. Medical

248 conditions associated with the toxic effects of smoking such as cardiovascular diseases or cancer,

249 usually do not appear in teenagers but rather during adulthood (Burns 2003). The most frequent

250 injuries resulting from smoking are burns, but burns only make up about 3.3\% of all unintentional

251 childhood injury deaths in high-income countries (Peden et al. 2009; Sacks \& Nelson 1994). The

252 missing applicability of the study conducted by Sacks \& Nelson as well as the rather small share

253 of burns in injury deaths could explain why the present study is silent on an association between

254 smoking and injuries.

255 Consistent with existing research, bullying victimisation as well as bullying others was

256 associated with increased injury occurrence. Being involved in bullying as a victim or perpetrator

257 goes along with an increased risk of physical fighting (Rudatsikira et al. 2008) which can lead to

258 injuries requiring medical attention. Physical fighting was, as mentioned, a significant risk factor

259 for suffering from injury in the present study.

260 The finding that living without mother increases risk for injury is supported by evidence

261 which shows that an increase of adults living within a household goes along with a decrease in

262 the risk of injury (Haynes et al. 2003). Parents also play a deciding role in teaching their children

263 about injury prevention, thus the reduction of parental contact may put adolescents at risk for

264 injuries (Wong \& Breslin 2017). Moreover, a study examining parenting differences between

265 mothers and fathers came to the conclusion that especially uninvolved maternal parenting can

266 lead to delinquency, depression, and decreased school commitment (Simons \& Conger 2007).

267 These findings may aid to demonstrate the protective effect involved parenting can have on the 
268 risk of adolescent injury occurrence. Our results only partially support these claims since we

269 could show that living without a mother was associated with an increase in injury occurrence

270 whereas living without a father showed no association with injury occurrence.

271 This study provides valuable insight into a largely neglected area of global health

272 research. To our knowledge this is the only study to have examined the epidemiology of injuries

273 among a school-based sample in Greenland. Despite that, the current study also had the following

274 limitations, since, besides giving valuable insight, it also remains confined and silent on several

275 topics.

276 First, the study does only include students that go to school and it does not include

277 adolescents that do not attend school at all. Research shows that those who are not in school may

278 be at even greater risk for injuries, yet assessing this would go beyond the scope of this study

279 (Dingli et al. 2012).

280 Secondly, some questions such as drug use, bullying, or physical fighting might have

281 altered our findings in in the form recall bias, as the participants had to recall information within

282 a rather large time frame which might have reduced their recall ability and accuracy (Celedonia et

283 al. 2013; Wilson et al. 2012). Also, all the questions were self-reported, which may have been

284 subject to social desirability and non-response bias (Acquah et al. 2014a).

285 Lastly, the cross-sectional nature of the dataset prevents us from drawing causal inference

286 from our findings. The results must be interpreted within their own time context. Longitudinal

287 data is necessary to establish the aforementioned causal pathways and to take into account the

288 nature of change over time. Still our results have value not only for the historical aggregation of

289 data, but they also play a role in understanding how young populations, and their behaviours,

290 might change over time. 
292 limited at present. Therefore, this study also stresses the need for further examination of this 293 topic.

The results of this study suggest that interpersonal relationships and conflicts are heavily linked

with injury occurrence among school-attending adolescents in Greenland. Future programs

should consider the risk behaviours that were found to have a negative association with the might modify the associations pointed out in this study.

Acquah E, L Wilson M, and Doku D. 2014a. Patterns and Correlates for Bullying among Young Adolescents in Ghana.

Acquah EO, Lloyd JK, Davis L, and Wilson ML. 2014b. Adolescent Physical Fighting in Ghana, Their Demographic and Social Characteristics. Social Sciences 3:227-241.

Agency USCI, and Office GP. 2016. The World Factbook 2016-17: Central Intelligence Agency. Avakov AV. 2015. Quality of Life, Balance of Power, and Nuclear Weapons (2015): A Statistical Yearbook for Statesmen and Citizens: Algora Publishing.

Blaabjerg AG, L. 2019. Statistics Greenland. Nuuk, Greenland.

Burns DM. 2003. Epidemiology of smoking-induced cardiovascular disease. Progress in cardiovascular diseases 46:11-29.

Bushman BJ, Newman K, Calvert SL, Downey G, Dredze M, Gottfredson M, Jablonski NG, Masten AS, Morrill C, Neill DB, Romer D, and Webster DW. 2016. Youth violence: What we know and what we need to know. Am Psychol 71:17-39. 10.1037/a0039687

Celedonia KL, Wilson ML, El Gammal HA, and Hagras AM. 2013. Physical fighting among Egyptian adolescents: social and demographic correlates among a nationally representative sample. PeerJ 1:e125-e125. 10.7717/peerj.125

Cherpitel CJ, Ye Y, Bond J, Borges G, and Monteiro M. 2015. Relative risk of injury from acute alcohol consumption: modeling the dose-response relationship in emergency department data from 18 countries. Addiction 110:279-288. 10.1111/add.12755

Currie C, Child UoE, Unit AHR, Children HBiS-a, and Organization WH. 2008. Inequalities in Young People's Health: HBSC International Report from the 2005/2006 Survey: WHO Regional Office for Europe.

David-Ferdon C, and Simon TR. 2014. Preventing Youth Violence: Opportunities for Action. Centers for Disease Control and Prevention. 
326

327

328

329

330

331

332

333

334

335

336

337

338

339

340

341

342

343

344

345

346

347

348

349

350

351

352

353

354

355

356

357

358

359

360

361

362

363

364

365

366

367

368

369

370

371

372

373

374

Dingli K, Buckley L, Reveruzzi B, Chapman R, Sheehan M, Block K, and Campus KG. 2012. Reducing road related injuries for young adolescents: an investigation of truancy as a risk factor. Australiasian road safety research, policing \& education workshop, Wellington, New Zealand. p 1-9.

Djerboua M, Chen BE, and Davison CM. 2016. Physical fighting, fighting-related injuries and family affluence among Canadian youth. BMC Public Health 16:199. 10.1186/s12889016-2886-3

Garmy P, Vilhjalmsson R, and Kristjansdottir G. 2018. Bullying in School-aged Children in Iceland: A Cross-sectional Study. J Pediatr Nurs 38:e30-e34. 10.1016/j.pedn.2017.05.009

Grydehøj A. 2014. Constructing a centre on the periphery: urbanization and urban design in the island city of Nuuk, Greenland. Island Studies Journal 9.

Harvey A, Towner E, Peden M, Soori H, and Bartolomeos K. 2009. Injury prevention and the attainment of child and adolescent health. Bulletin of the World Health Organization 87:390-394. 10.2471/blt.08.059808

Haynes R, Reading R, and Gale S. 2003. Household and neighbourhood risks for injury to 5-14 year old children. Social science \& medicine 57:625-636.

Karsberg SH, Lasgaard M, and Elklit A. 2012. Victimisation and PTSD in a Greenlandic youth sample. Int J Circumpolar Health 71. 10.3402/ijch.v71i0.18378

Knapik JJ, and Bedno SA. Epidemiologic Evidence and Possible Mechanisms for the Association Between Cigarette Smoking and Injuries. Part 2: Is the Relationship Between Smoking and Injuries Causal? J Spec Oper Med 18:117-122.

Kobusingye O, Bowman B, Burrows S, Matzopoulos R, and Butchart A. 2010. Violence and health in the WHO African region. Brazzaville: WHO Regional Office for Africa.

Laflamme L, Engström K, Möller J, Alldahl M, and Hallqvist J. 2002. Bullying in the school environment: an injury risk factor? Acta Psychiatrica Scandinavica 106:20-25.

Lozano R, Naghavi M, Foreman K, Lim S, Shibuya K, Aboyans V, Abraham J, Adair T, Aggarwal R, Ahn SY, Alvarado M, Anderson HR, Anderson LM, Andrews KG, Atkinson C, Baddour LM, Barker-Collo S, Bartels DH, Bell ML, Benjamin EJ, Bennett D, Bhalla K, Bikbov B, Bin Abdulhak A, Birbeck G, Blyth F, Bolliger I, Boufous S, Bucello C, Burch M, Burney P, Carapetis J, Chen H, Chou D, Chugh SS, Coffeng LE, Colan SD, Colquhoun S, Colson KE, Condon J, Connor MD, Cooper LT, Corriere M, Cortinovis M, de Vaccaro KC, Couser W, Cowie BC, Criqui MH, Cross M, Dabhadkar KC, Dahodwala N, De Leo D, Degenhardt L, Delossantos A, Denenberg J, Des Jarlais DC, Dharmaratne SD, Dorsey ER, Driscoll T, Duber H, Ebel B, Erwin PJ, Espindola P, Ezzati M, Feigin V, Flaxman AD, Forouzanfar MH, Fowkes FG, Franklin R, Fransen M, Freeman MK, Gabriel SE, Gakidou E, Gaspari F, Gillum RF, Gonzalez-Medina D, Halasa YA, Haring D, Harrison JE, Havmoeller R, Hay RJ, Hoen B, Hotez PJ, Hoy D, Jacobsen KH, James SL, Jasrasaria R, Jayaraman S, Johns N, Karthikeyan G, Kassebaum N, Keren A, Khoo JP, Knowlton LM, Kobusingye O, Koranteng A, Krishnamurthi R, Lipnick M, Lipshultz SE, Ohno SL, Mabweijano J, MacIntyre MF, Mallinger L, March L, Marks GB, Marks R, Matsumori A, Matzopoulos R, Mayosi BM, McAnulty JH, McDermott MM, McGrath J, Mensah GA, Merriman TR, Michaud C, Miller M, Miller TR, Mock C, Mocumbi AO, Mokdad AA, Moran A, Mulholland K, Nair MN, Naldi L, Narayan KM, Nasseri K, Norman P, O'Donnell M, Omer SB, Ortblad K, Osborne R, Ozgediz D, Pahari B, Pandian JD, Rivero AP, Padilla RP, Perez-Ruiz F, Perico N, Phillips D, Pierce K, Pope CA, 3rd, Porrini E, Pourmalek F, Raju M, Ranganathan D, Rehm JT, Rein DB, Remuzzi G, Rivara FP, Roberts T, De Leon FR, Rosenfeld LC, Rushton L, Sacco RL, Salomon JA, Sampson U, Sanman E, Schwebel DC, Segui-Gomez M, Shepard DS, Singh D, Singleton J, Sliwa K, Smith E, Steer A, Taylor JA, Thomas B, Tleyjeh IM, Towbin JA, Truelsen T,

PeerJ reviewing PDF | (2019:08:39958:2:0:NEW 2 Jan 2020) 
375

376

377

378

379

380

381

382

383

384

385

386

387

388

389

390

391

392

393

394

395

396

397

398

399

400

401

402

403

404

405

406

407

408

409

410
Undurraga EA, Venketasubramanian N, Vijayakumar L, Vos T, Wagner GR, Wang M, Wang W, Watt K, Weinstock MA, Weintraub R, Wilkinson JD, Woolf AD, Wulf S, Yeh PH, Yip P, Zabetian A, Zheng ZJ, Lopez AD, Murray CJ, AlMazroa MA, and Memish ZA. 2012. Global and regional mortality from 235 causes of death for 20 age groups in 1990 and 2010: a systematic analysis for the Global Burden of Disease Study 2010. Lancet 380:2095-2128. 10.1016/s0140-6736(12)61728-0

Niclasen BVL, and Bjerregaard P. 2007. Review Article: Child health in Greenland. Scandinavian Journal of Public Health 35:313-322. 10.1080/14034940600975781

Peden M, Oyegbite K, Ozanne-Smith J, Hyder AA, Branche C, Rahman A, Rivara F, and Bartolomeos K. 2009. World report on child injury prevention: World Health Organization Geneva.

Pinheiro PS, and Children UNS-GsSoVA. 2006. World Report on Violence Against Children.

Rehm J, and Shield KD. 2013. Global alcohol-attributable deaths from cancer, liver cirrhosis, and injury in 2010. Alcohol Res 35:174-183.

Rudatsikira E, Muula AS, and Siziya S. 2008. Variables associated with physical fighting among US high-school students. Clin Pract Epidemiol Ment Health 4:16. 10.1186/1745-0179-416

Sacks JJ, and Nelson DE. 1994. Smoking and injuries: an overview. Preventive medicine 23:515520.

Schnohr C, and Niclasen BV. 2006. Bullying among Greenlandic schoolchildren: development since 1994 and relations to health and health behaviour. Int J Circumpolar Health 65:305312. 10.3402/ijch.v65i4.18127

Simons LG, and Conger RD. 2007. Linking mother-father differences in parenting to a typology of family parenting styles and adolescent outcomes. Journal of Family Issues 28:212-241.

Siqueira L, Diab M, Bodian C, and Rolnitzky L. 2000. Adolescents becoming smokers: the roles of stress and coping methods. J Adolesc Health 27:399-408.

Skala K, and Walter H. 2013. Adolescence and Alcohol: a review of the literature. Neuropsychiatr 27:202-211. 10.1007/s40211-013-0066-6

Valdez C, Radomski M, Renne C, Amdur R, Dunne J, and Sarani B. 2016. Alcohol level and injury severity: is the floppy patient myth true? J Surg Res 200:664-668. 10.1016/j.jss.2015.10.001

Wilson ML, Dunlavy AC, Viswanathan B, and Bovet P. 2012. Suicidal expression among school-attending adolescents in a middle-income sub-Saharan country. Int J Environ Res Public Health 9:4122-4134. 10.3390/ijerph9114122

Wong IS, and Breslin FC. 2017. Risk of work injury among adolescent students from single and partnered parent families. American journal of industrial medicine 60:285-294. 


\section{Table $\mathbf{1}$ (on next page)}

Table 1. Distribution of selected factors according to categories of injury occurrence among school attending adolescents in Greenland. (2005/2006) 
Table 1 (referred to as 'Table 1'). Distribution of selected factors according to categories of injury occurrence among school attending adolescents in Greenland. (2005/2006)

\begin{tabular}{|c|c|c|c|c|}
\hline & $\begin{array}{l}\text { No Injuries } \\
(n=1456)\end{array}$ & $\begin{array}{l}\text { 1-2 Injuries } \\
(n=503)\end{array}$ & 3+ Injuries $(n=116)$ & P-Value \\
\hline Age (mean) & 13.4 & 13.4 & 13.2 & 0.480 \\
\hline Gender (male) & 43.4 & 56.7 & 62.1 & $<0.001$ \\
\hline VPA ( $\geq 4$ days) & 48.2 & 53.4 & 44.5 & 0.082 \\
\hline VPA outside school ( $\geq 4$ days) & 49.1 & 52.5 & 60.2 & 0.048 \\
\hline Smoking (Yes) & 35.5 & 35.9 & 39.8 & 0.666 \\
\hline Alcohol misuse ( $\geq 2 /$ month) & 10.0 & 12.5 & 14.0 & 0.168 \\
\hline $\begin{array}{l}\text { Bullying victimisation } \\
\text { ( } \geq 2 / \text { month })\end{array}$ & 32.6 & 46.9 & 54.4 & $<0.001$ \\
\hline $\begin{array}{l}\text { Bullying perpetrator } \\
(\geq 2 / \text { month })\end{array}$ & 39.5 & 50.4 & 52.2 & $<0.001$ \\
\hline Physical fighting ( $\geq 2$ fights) & 8.7 & 16.4 & 33.3 & $<0.001$ \\
\hline Job father (Skilled job) & 42.4 & 38.4 & 45.3 & 0.352 \\
\hline Job mother (Skilled job) & 47.6 & 48.6 & 41.7 & 0.516 \\
\hline Talk to same gender & & & & 0.222 \\
\hline Very easy $(n=701)$ & 49.3 & 44.0 & 39.8 & \\
\hline Easy $(\mathrm{n}=528)$ & 34.7 & 38.2 & 38.6 & \\
\hline Hard $(\mathrm{n}=141)$ & 9.3 & 10.0 & 10.8 & \\
\hline Very hard $(\mathrm{n}=52)$ & 3.3 & 4.4 & 2.4 & \\
\hline $\begin{array}{l}\text { Does not have/see this } \\
\text { person }(n=56)\end{array}$ & 3.5 & 3.3 & 8.4 & \\
\hline Talk to opposite gender & & & & 0.229 \\
\hline Very easy $(n=383)$ & 28.3 & 28.0 & 29.2 & \\
\hline Easy $(\mathrm{n}=423)$ & 31.7 & 30.7 & 29.2 & \\
\hline Hard $(\mathrm{n}=281)$ & 21.6 & 19.8 & 13.9 & \\
\hline Very hard (n = 135) & 9.1 & 12.5 & 9.7 & \\
\hline $\begin{array}{l}\text { Does not have/see this } \\
\text { person }(n=132)\end{array}$ & 9.3 & 9.1 & 18.1 & \\
\hline Self-assessed wealth & & & & 0.478 \\
\hline Well-off ( $n=139)$ & 19.2 & 18.1 & 23.0 & \\
\hline Average (n = 1394) & 72.9 & 75.7 & 72.0 & \\
\hline Not well-off $(n=363)$ & 7.9 & 6.2 & 5.0 & \\
\hline Live without mother & 19.9 & 23.6 & 29.4 & 0.024 \\
\hline Live without father & 39.5 & 37.2 & 45.9 & 0.235 \\
\hline Live without both parents & 13.2 & 13.6 & 17.4 & 0.457 \\
\hline Live with both parents & 53.4 & 52.3 & 42.2 & 0.077 \\
\hline
\end{tabular}

Notes.

All variables are expressed as proportions (in \%) except for age (mean). 
Table 2 (on next page)

Table 2. Odds ratios and $95 \%$ confidence intervals for injury-influencing factors among school attending adolescents in Greenland. Adjusted for all significant variables. (2005-2006) 
Table 2 (referred to as 'Table 2'). Odds ratios and 95\% confidence intervals for injuryinfluencing factors among school attending adolescents in Greenland. Adjusted for all significant variables. (2005-2006)

\begin{tabular}{|l|l|l|l|l|}
\hline & $\begin{array}{l}\text { 1-2 Injuries, OR } \\
\text { (95\% confidence } \\
\text { intervals) }\end{array}$ & P-Value & $\begin{array}{l}\text { 3+ Injuries, OR } \\
\text { (95\% confidence } \\
\text { intervals) }\end{array}$ & P-Value \\
\hline Gender & $1.54(1.23-1.93)$ & $<0.001$ & $1.62(1.05-2.51)$ & 0.030 \\
\hline VPA outside school & $1.08(0.86-1.34)$ & 0.510 & $1.30(0.85-1.98)$ & 0.228 \\
\hline Physical fighting & $1.58(1.14-2.20)$ & 0.006 & $3.42(2.09-5.59)$ & $<0.001$ \\
\hline Bullying victimisation & $1.58(1.25-1.99)$ & $<0.001$ & $2.29(1.48-3.54)$ & $<0.001$ \\
\hline Bullying perpetrator & $1.26(1.00-1.59)$ & 0.051 & $1.15(0.74-1.79)$ & 0.530 \\
\hline Live without mother & $1.19(0.92-1.56)$ & 0.185 & $1.45(0.91-2.32)$ & 0.116 \\
\hline
\end{tabular}

Reference category = no injuries 


\section{Table 3(on next page)}

Table 3. Odds ratios and $95 \%$ confidence intervals for injury-influencing factors among school attending adolescents in Greenland. Adjusted for age and gender. (2005/2006) 
Table 3 (referred to as 'Table 3'). Odds ratios and 95\% confidence intervals for injuryinfluencing factors among school attending adolescents in Greenland. Adjusted for age and gender. (2005/2006)

\begin{tabular}{|l|l|l|l|l|}
\hline & $\begin{array}{l}\text { 1-2 Injuries, OR } \\
\text { (95\% confidence } \\
\text { intervals) }\end{array}$ & P-Value & $\begin{array}{l}\text { 3+ Injuries, OR } \\
\text { (95\% confidence } \\
\text { intervals) }\end{array}$ & P-Value \\
\hline Gender & $1.70(1.39-2.09)$ & $<0.001$ & $2.13(1.44-3.14)$ & $<0.001$ \\
\hline VPA outside school & $1.05(0.85-1.30)$ & 0.652 & $1.38(0.93-2.06)$ & 0.108 \\
\hline Physical fighting & $1.82(1.33-2.47)$ & $<0.001$ & $4.47(2.86-7.01)$ & $<0.001$ \\
\hline Bullying victimisation & $1.81(1.47-2.24)$ & $<0.001$ & $2.43(1.65-3.57)$ & $<0.001$ \\
\hline Bullying perpetrator & $1.53(1.25-1.89)$ & $<0.001$ & $1.67(1.13-2.45)$ & $<0.001$ \\
\hline Live without mother & $1.21(0.94-1.56)$ & 0.133 & $1.63(1.05-2.52)$ & 0.028 \\
\hline
\end{tabular}

Reference category $=$ no injuries 